\title{
Developing a Course to Choose an Engineering Major at Colleges with a Pre-Engineering Program Only
}

\author{
https://doi.org/10.3991/ijep.v10i4.12987 \\ Il Yoon $(\bowtie)$ \\ University of North Georgia, Georgia, USA \\ i yooneung.edu
}

\begin{abstract}
Colleges having their various engineering departments can offer courses to help students choose their engineering major with the support of faculty and lab activities from various engineering departments. However, students at colleges with a pre-engineering program only usually cannot have the support from various engineering departments. Therefore, a new course was designed to help them decide whether they should study engineering or help them choose their engineering major. This new course consists of three parts: conducting projects related to various engineering majors, preparing presentations related to various engineering majors, and listening to presentations on the general information of engineering. A survey was conducted to measure the effectiveness of this new course offered in the author's institution. Results show that $87 \%$ of the respondents answered that conducting projects help them know better the engineering major they choose, and $84 \%$ of the respondents answered that preparing and presenting presentations help them know better the engineering major that they choose. Therefore, this course is very effective for students to gain knowledge of various engineering majors to choose their engineering discipline.
\end{abstract}

Keywords - Pre-engineering; First year curriculum; Career choice; Project based learning

\section{Introduction}

Although the number of undergraduate enrollment of full-time engineering students had increased steadily, a considerable percentage of students who entered an engineering program changed their major to a non-engineering major [1], [2]. That is, a good number of students enter engineering schools without adequately knowing what engineering is. There are various reasons that students choose to study engineering. There have been studies on factors influencing students to study or not study engineering as their major [3]-[7]. According to these studies, some common reasons that students initially choose to study engineering are being good at math/science, future job opportunities, an interest in building, and the influence of family. From these prevailing reasons, it can be thought that many students enter engineering programs without a good understanding of what engineering is. Thus, it is important to help the students under- 
stand what engineering is, so that they can determine whether they should study engineering. Another important thing is to have good knowledge of various engineering disciplines, so that engineering students choose the right engineering discipline for their career. Therefore, it is also essential to help the engineering students develop a thorough understanding of their engineering discipline that they plan to study, so that they can determine whether they keep studying the engineering discipline.

There are a limited number of studies about factors influencing students' choice of engineering major within engineering disciplines. One of the studies showed that selfexploration is the most influential factor. However, the concept of self-exploration is multi-faceted. Thus, the study suggests further research to identify the self-exploration aspect in detail [8]. Another study found that socializers, self-identified competence, and media resources influence students on choosing their engineering major [9]. Some quotes from students regarding why they chose their engineering major were presented [10]. The most recent study revealed that future job opportunities, the potential for societal contribution, and personal interests are the most influential factors [11].

While many factors influence students' choice on the specific engineering major they choose, providing a course to give information on various engineering majors would be one effective way to help the engineering students choose their major. It was found that $64 \%$ of ABET (Accreditation Board for Engineering and Technology) EAC (Engineering Accreditation Commission) - accredited engineering programs in the USA offer a form of Introduction to Engineering course for the 1st year engineering students, and all majors require the course or some majors depending on the institution [12]. Though many institutions having engineering programs offer some form of Introduction to Engineering course, it is unclear what percentage of them offer the Introduction to Engineering course to help students choose their engineering major. A minimal number of papers about the course designed to help engineering students choose their engineering discipline have been published so far.

At the University of Florida, the Introduction to Engineering course includes lab activities provided by each engineering department. The lab activities are designed to help students gain information about each engineering major [13]. At Purdue University, students take a course providing lectures focusing on each engineering major. Besides the course, four engineering schools at Purdue University offer their introductory course to provide more detailed information about each discipline [14]. At Vanderbilt University, a group of students, who declare the same engineering major, choose and conduct a project out of a project list of the major. Also, students join a series of panel discussions of each engineering major to gain information about each engineering discipline [15]. At Binghamton University, four introductory engineering courses are offered to the 1st year engineering students. Two of them provide lectures and lab activities in several areas of engineering. They also provide guest lectures by representatives from each engineering department [16]. At the University of Portland, the Introductory to Engineering course provides resources and activities including, but not limited to, projects, presentations, alumni videos and club meetings to help students choose their engineering major [17]. At Langara College, an introductory engineering course is offered to introduce the different disciplines of engineering by guest lecturers [18]. 
The Introductory to Engineering courses described in the previous paragraph are offered at the institutions that have their various engineering departments. That is, those institutions can offer the introductory engineering course with support from faculty and lab activities from various engineering departments. However, there are a good number of colleges that only have a pre-engineering program. Those colleges mostly would not have the faculty or labs of various engineering departments like those institutions that have their various engineering departments. Thus, students of those institutions may not have opportunities to adequately learn about each engineering discipline from the Introductory to Engineering course due to the lack of various engineering departments. That means the students are asked to declare their engineering major without having a thorough understanding of the various engineering majors when they transfer to a 4year engineering school to complete their engineering degree. Therefore, there is a need to develop an Introductory to Engineering course specifically designed for pre-engineering students at the institutions that have a pre-engineering program only.

In this paper, a new course is suggested to help the pre-engineering students at the colleges that have a pre-engineering program only. Though these colleges do not have any supportive resources from various engineering departments, this course was designed to provide useful information about engineering and various engineering majors to help the students make informed decisions. The new course consists of three parts: conducting projects related to various engineering majors, preparing presentations related to various engineering majors, and listening to presentations on general information about engineering. A survey about the effect of conducting projects and preparing presentations on students' decision was carried out and analyzed after one semester of this new course.

\section{Course Descriptions}

\subsection{Conducting projects related to various engineering majors}

Due to the lack of various engineering majors at the colleges that have a pre-engineering program only, students lack supportive resources from the various engineering departments. As a result, students cannot have any lab activities that can be provided from various engineering departments. Thus, this course was designed to provide useful information about various engineering majors without any supportive resources from the various engineering departments. In this course, students are asked to conduct projects related to each engineering major. Each project was designed to be conducted in a classroom without using any lab resources from various engineering departments. A list of projects related to each engineering major is presented in Table 1 . The engineering disciplines in the table were chosen based on popularity. That is, most students in the author's institution plan to study the engineering disciplines listed in the table. By conducting projects related to each engineering major, students who do not choose their engineering major can experience the characteristics of the project of each engineering major, so that they can have a better understanding to select their engineering major after this course. For the students who already chose their engineering major before 
taking this course, they can enhance or confirm whether their choice of engineering fits them by conducting the project in their engineering major. If they find out that their initial choice of engineering major does not suit them, then they can explore other engineering disciplines by conducting projects in other engineering majors.

Table 1. A list of projects related to each engineering major.

\begin{tabular}{|l|l|}
\hline \multicolumn{1}{|c|}{ Majors } & \multicolumn{1}{c|}{ Projects } \\
\hline Aerospace Engineering & Rubber band powered airplane \\
\hline Civil Engineering & Movable popsicle hydraulic bridge \\
\hline Mechanical Engineering & Model manual gearbox \\
\hline Electrical Engineering & Digital signal processing \\
\hline Robotics Engineering & Line tracking robot \\
\hline Computer Science and Engineering & Model self-driving vehicle \\
\hline
\end{tabular}

The practical purpose of conducting projects in various engineering fields is to figure out whether an individual student finds fun, interest, or aptitude in a specific engineering discipline. An instructor gives basic instructions and related knowledge before students work on each project. However, the basic instructions and related knowledge are to be as minimized as possible. This is because it is intended that students try to think and find solutions on their own to accomplish the project in each engineering major. From this process, it is expected that students may find fun, interest, or aptitude in a specific engineering major.

For the project related to aerospace engineering, students learn the basics of Bernoulli's principle and angle of attack in class from the instructor. Then, they are asked to design and build a model airplane powered by rubber bands. They are asked to utilize the knowledge of the basics of Bernoulli's principle and angle of attack gained from the class to design their model airplane. They are allowed to buy multiple model airplanes that are commercially available and combine parts to achieve the best performance. An example of a rubber band airplane is shown in Fig 1. For evaluation, the shape of the cross-section of an airfoil is considered, and the angle of attack is measured. Flight time of the airplane is also measured to test the performance.

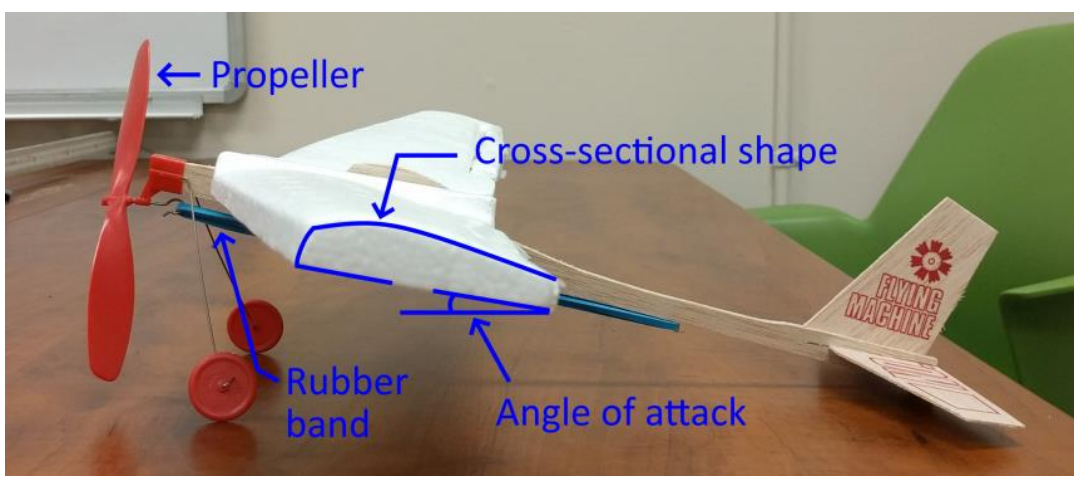

Fig. 1. An example of a rubber band airplane as an aerospace engineering project. 
For the civil engineering project, students learn different types of movable bridges, a truss structure, and a hydraulic system. Then, they are asked to build a movable hydraulic bridge with popsicle sticks, two syringes with different sizes, and a tube. When building the bridge, students are encouraged to think about how they design the structure of the bridge, so that their bridge is sturdy. Also, students are asked to figure out, from the knowledge of a hydraulic system that they learn in class, whether the syringe attached to the bridge needs to be the bigger one, or the smaller one. An example of a movable popsicle hydraulic bridge is shown in Fig 2. For evaluation, the structure of the bridge, including truss structures, is accessed. It is also evaluated whether the syringes are attached to the right sides. In other words, it will be checked whether the big syringe is attached to the bridge side, and the small syringe is used for operating the syringe hydraulic system. The performance of the bridge, which is opening and closing the bridge with the syringes, is also evaluated.

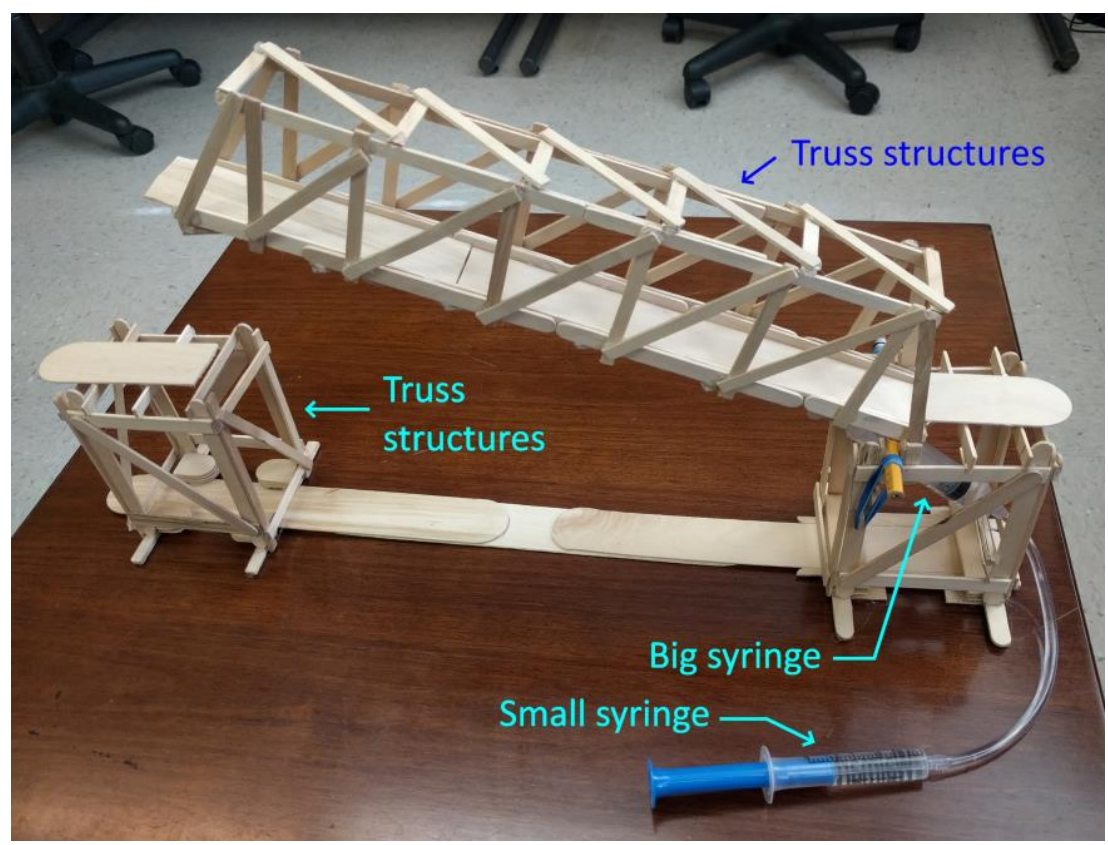

Fig. 2. An example of a movable popsicle hydraulic bridge as a civil engineering project.

For the mechanical engineering project, students learn a principle of a simple manual transmission. Then, they are asked to design and construct a 3-speed manual gearbox mimicking the simple manual transmission using Lego EV3. Also, they are asked to transmit rotational motion from the gearbox to wheels using bevel gears. An example of a gearbox is shown in Fig 3. If students add a gear set for reverse direction, bonus points are given. For evaluation, gear ratios for each speed are inspected so that the gearbox can have three speeds, which is low speed, medium speed, and high speed. Also, students are asked to operate the gearbox to show that the gearbox successfully 
changes its speeds. A motor is attached to the gearbox to give rotational motion while switching the speeds.

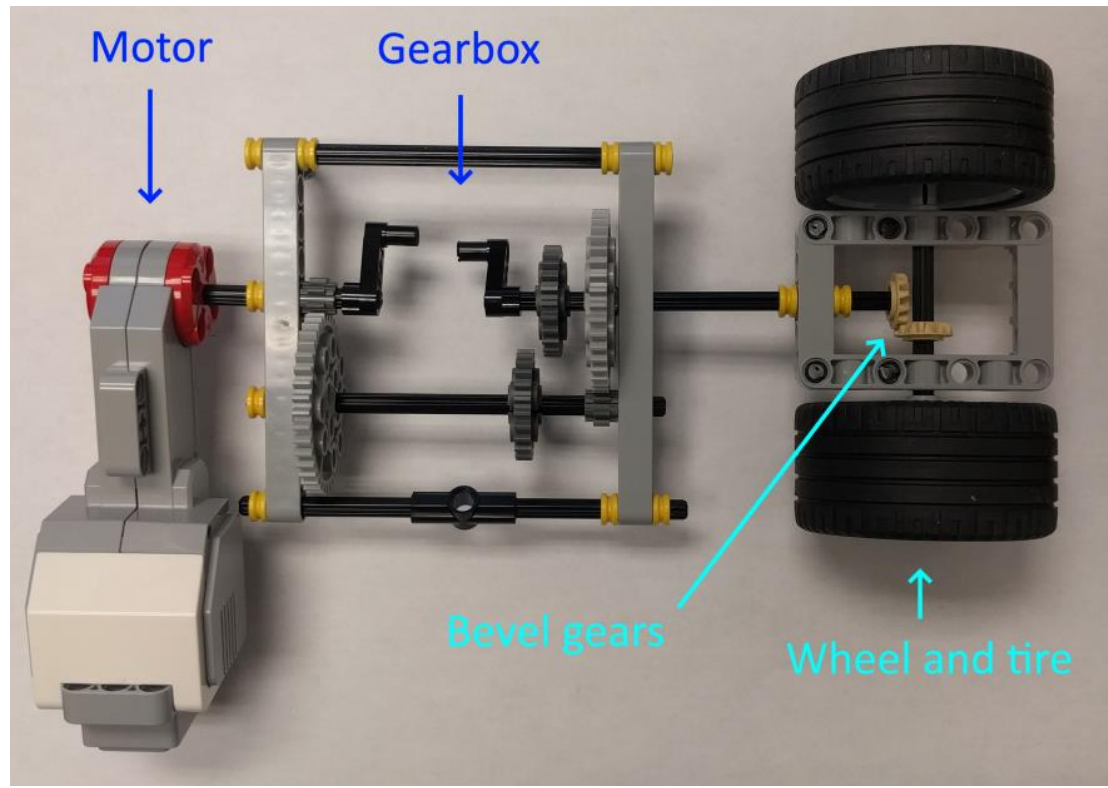

Fig. 3. An example of a gearbox as a mechanical engineering project.

For the electrical engineering project, students learn the basics of the sound frequency, fast Fourier transform (FFT), and bandpass filters. Then, they are asked to remove a high-frequency noise such as beep sound, or low-frequency noise such as jet noise from sound files. Because most students are not familiar at all with the concepts for this project, a Matlab code is given to students. What students need to do is understanding the basics of sound frequency and the concept of bandpass filters. Then, students are asked to pick the right frequencies to remove noises from FFT analysis data, and they need to choose either the low bandpass filter or the high bandpass filter. Then, they type some input parameters into the given Matlab code to remove the noises. An example of applying a low bandpass filter for removing beep noise is shown in Fig 4. For evaluation, it is checked whether students can choose the right bandpass filter, which is either high bandpass filter or low bandpass filter, to remove noises. It is also checked whether students can determine the frequency for the bandpass filter that they choose to remove noises. Students are asked to modify MATLAB codes to display a frequency spectrum to determine the right frequency and apply the bandpass filters. 


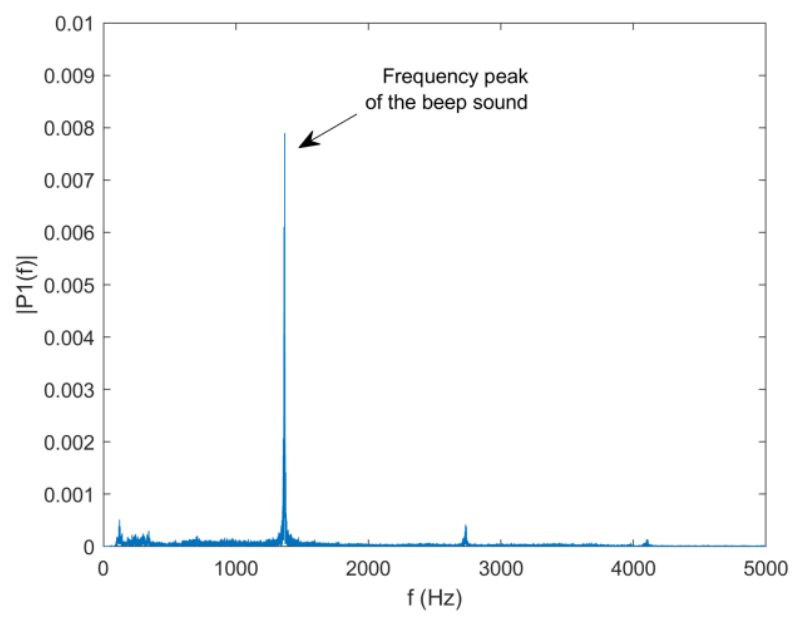

a) The frequency spectrum of a sample sound including beep noise

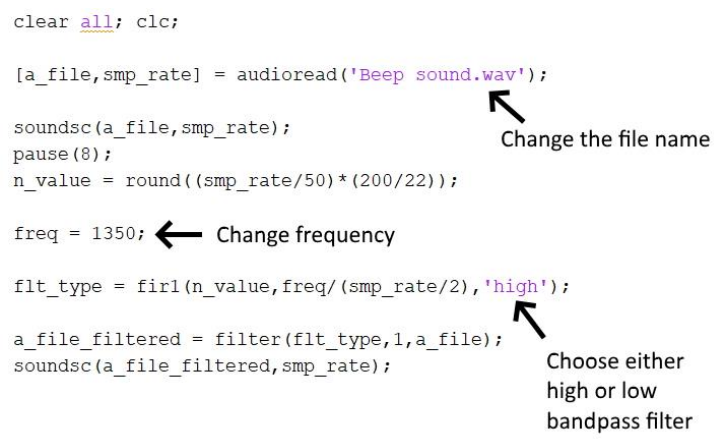

b) A sample code given to students to modify

Fig. 4. An example of a bandpass filter application as an electrical engineering project.

For the robotics engineering project, students are asked to build a simple model car using Lego EV3. Then, they are asked to write a Matlab code to make the car follow a line on the floor. Because most students would not have any programming experiences before taking this course, especially with Matlab, students learn how to use Matlab step by step from the beginning of the semester until they work on the Robotics project. An example of the model car is shown in Fig 5. For evaluation, algorithms, and flowcharts that students make are graded. MATLAB codes that students write for the algorithms are examined as well. 


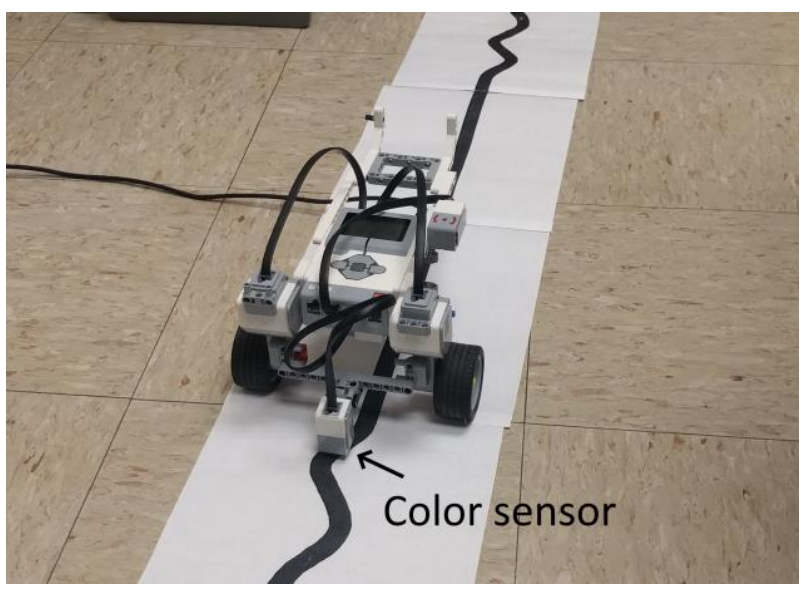

Fig. 5. An example of a model car tracking a line as a robotics project.

For the computer science and engineering project, students are asked to build a model self-driving car using Lego EV3, Matlab, and a web camera. The model selfdriving car detects lines of the track on the floor using a web camera and image processing techniques. Then, the car changes its direction depending on the detected lines as it moves forward. An example of a model self-driving car is shown in Fig 6. The detected lines are drawn with green color in figure (b). If students add an algorithm to make the car stop when it detects an obstacle on the track using an ultrasonic sensor, bonus points are given. To build the self-driving car, including a Matlab code, students learn the basics of image processing techniques using Matlab in class. Step-by-step instructions will be given for writing code for this project because the difficulty level of this project is relatively higher than other projects in this course.

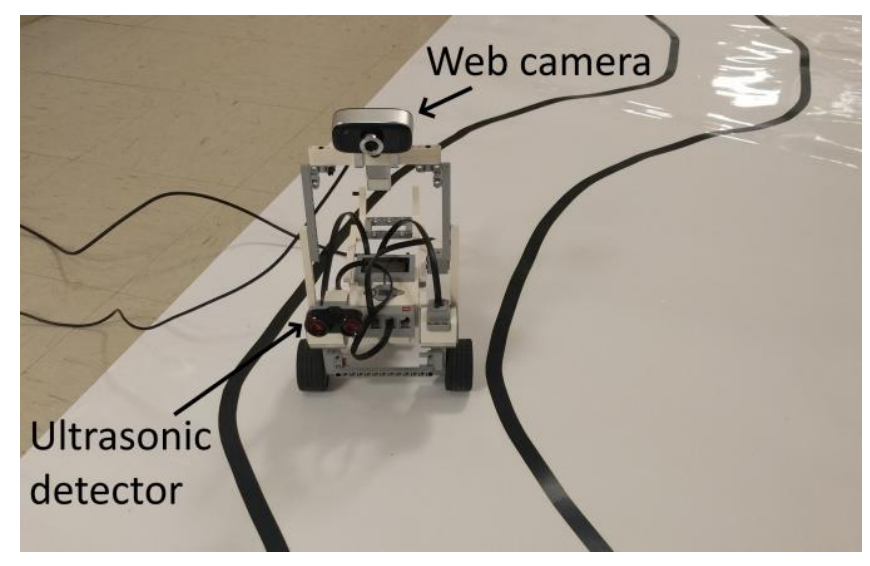

a) A model sefl-driving car 


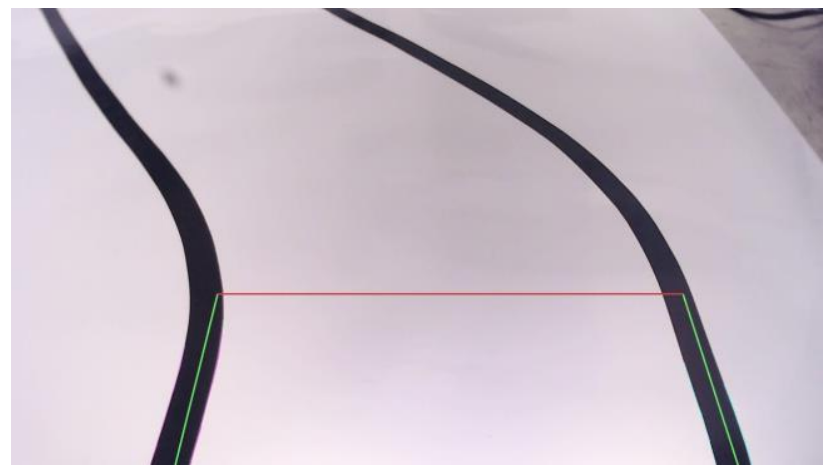

b) Green lines are drawn on a still image after detecting track lines using MATLAB

Fig. 6. An example of a model self-driving car as a computer science and engineering project.

After students finish all projects related to the various engineering majors, they are asked to conduct an open-ended project. For the open-ended project, students are asked to design and build a prototype of a product that they would like to develop for three weeks. At the end of the semester, a survey regarding students' attitudes, enthusiasm, and motivations on each project is conducted. The questions for the survey are modified from an existing assessment tool [19] and are shown in Table 2. Students can choose one out of five choices for each project: Strongly disagree, Disagree, Neither agree nor disagree, Agree, Strongly agree.

Table 2. Survey questions regarding students' attitudes, enthusiasm, and motivations on each project.

\begin{tabular}{|l|l|}
\hline 1. & Did you feel enthusiastic when conducting each project? \\
\hline 2. & Did you feel confident about conducting each project? \\
\hline 3. & Did you feel motivated to conduct each project? \\
\hline 4. & Did you feel difficult while conducting each project? \\
\hline 5. & Did you feel forced to conduct each project? \\
\hline
\end{tabular}

As mentioned earlier, the projects suggested in this course can be performed without any supportive resources from the respective engineering departments. Thus, these projects are ideal for institutions that have a pre-engineering program only.

\subsection{Preparing presentations related to various engineering majors}

Students are asked to prepare a presentation related to an engineering major that they are interested in or they plan to study. Then, they present it in class. The benefit of preparing the presentation is that students learn more effectively about their engineering major when they prepare the presentation on their own, rather than simply listening to 
a lecture about the engineering major in the class. Therefore, students gain a more thorough understanding of the engineering major that they are interested in while they are preparing the presentation.

Additionally, students who do not choose their engineering major before taking this course can learn about each engineering major by listening to presentations that other students prepare. However, students would not have a good idea of what to prepare for their presentation. Thus, a brief guide, including the contents of the presentation, is given to students before they prepare. The guide with the contents that students are required to put in their presentation is shown in Table 3.

Table 3. Contents required to be in presentations related to each engineering major.

\begin{tabular}{|l|l|}
\hline 1. & Contents for presentations \\
\hline 2. & Introduction: What is $* * *$ Engineering? \\
\hline 3. & What are the branches of $* * *$ Engineering? \\
\hline 4. & Brief descriptions of each branch in $* * *$ Engineering. \\
\hline 5. & What or how do engineers work in each branch? \\
\hline 6. & What are the major courses *** Engineering students need to take? \\
\hline 7. & What is the average entry-level and experienced-level salary of $* * *$ Engineers? \\
\hline
\end{tabular}

***Represents each engineering major, such as aerospace, civil, mechanical, etc.

\subsection{Presentations on the general information of engineering}

The presentations on the general information of engineering are prepared and presented by an instructor of the course. The topics of the presentations are shown in Table 4. The time duration of each presentation is about 25 minutes. The contents of the presentations are from "Engineering Your Future, A Comprehensive Introduction to Engineering" [18]. This book is used as the textbook for the course. A mid-term is given to evaluate students' understanding of each topic in the table. A survey is given at the end of a semester to assess students' attitudes on each topic in the table. Survey questions are shown in Table 5. Students can choose one out of five choices for each project: Strongly disagree, Disagree, Neither agree nor disagree, Agree, Strongly agree.

Table 4. A list of topics for the presentations on the general information of engineering.

\begin{tabular}{|l|l|}
\hline 1. & List \\
\hline 2. & Engineering: Introduction 1 \\
\hline 3. & Engineering: Introduction 2 \\
\hline 4. & Creativity and problem solving \\
\hline 5. & Projects \\
\hline 6. & Design \\
\hline 7. & Communication \\
\hline 8. & Teamwork \\
\hline 9. & Engineering Ethics \\
\hline
\end{tabular}


Table 5. Survey questions regarding students' attitudes on each topic of the presentations.

\begin{tabular}{|c|l|}
\hline 1. & Did each presentation draw your interest to the topic? \\
\hline 2. & Did you enjoy learning about the topic? \\
\hline 3. & Did you feel confident in your knowledge about the topic after listening? \\
\hline
\end{tabular}

\section{Methods}

A survey was conducted after this newly suggested course was offered. This course was offered at the author's institution in the USA in the fall semester of 2018. The course name was "Introduction to Engineering." Three sections of the same course were offered at different time slots by the author. A survey was conducted to evaluate the effectiveness of this course at the last class of the semester for all three sections. All questions are multiple-choice questions. Sheets of paper with questions were given to students during the class hours, and all students in the classes were asked to take the survey. About 15 minutes were given to answer the questions of the survey. In total, 52 students conducted the survey. After the survey, answers were collected, and the data were prepared from the answers.

\section{$4 \quad$ Results and Discussions}

In Fig 7, the survey responses for a question whether this course help students understand what engineering is and what engineers do are shown. It shows that $34 \%$ (18 out of 52) of the respondents answered "Strongly Agree," and $58 \%$ (30 out of 52) of the respondents answered, "Agree." In total, $92 \%$ of the responses answered that they understand what engineering is and how engineers work after taking this course. It also shows that none of the students answered "Disagree" nor "Strongly Disagree" to this question. The results shown in this figure is very promising because it shows that more than $90 \%$ of students learned what they are supposed to learn from this course, and there was no negative response. 

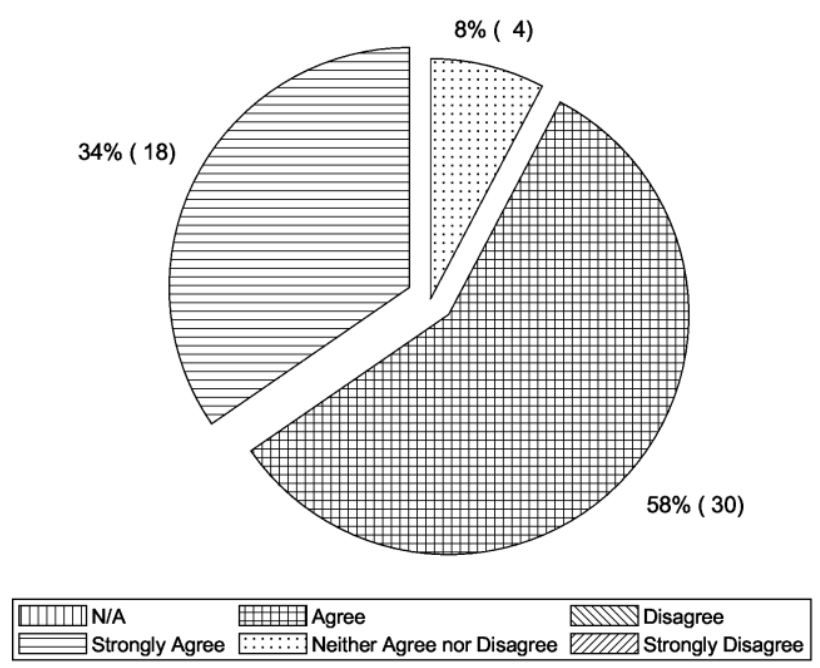

Fig. 7. Understanding Engineering and Engineers after taking this course.

Out of 52 respondents, responses from Fig 8 to Fig 11 are only from the students who already determined their engineering major before taking this course. A question was given to check whether they already determined their engineering discipline. 38 students out of 52 answered that they already determined their engineering major, and 13 students answered that they did not. That is, 38 students already chose their engineering major before taking this course, while 13 students did not. One student did not answer this question for an unknown reason.

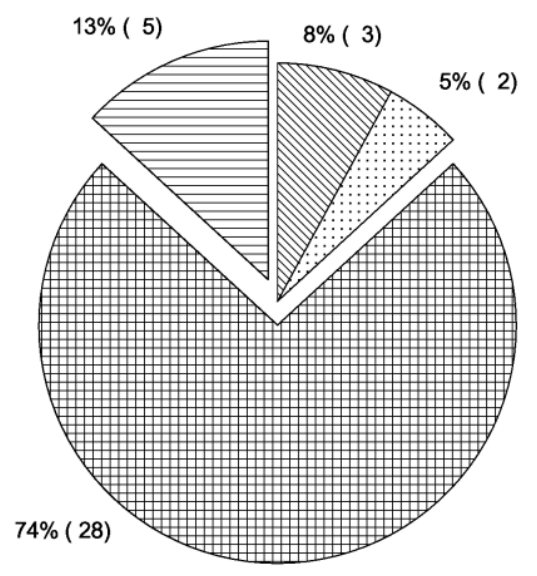

\begin{tabular}{|c|c|c|}
\hline N/III & $\begin{array}{l}1 \text { Agree } \\
\ldots \ldots: 2 \text { Neither Agree nor Disagree }\end{array}$ & 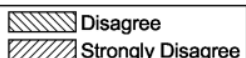 \\
\hline
\end{tabular}

Fig. 8. Projects help students know better the engineering major that they choose. 
In Fig 8, it shows the responses to a question; whether conducting projects related to the engineering major that students chose to study before taking this course is helpful to know their engineering major better. The data shows that $13 \%$ (5 out of 38 ) of the respondents answered "Strongly Agree," and 74\% (28 out of 38) of the respondents answered, "Agree." In total, 87\% (33 out of 38) of the respondents answered that it is helpful. In Fig 9, it shows the responses of a question of whether preparing and presenting the presentation related to the engineering major that students chose to study before taking this course helps understand their engineering major better. The data shows that 26\% (10 out of 38) of the respondents answered "Strongly Agree," and 58\% (22 out of 38 ) of the respondents answered, "Agree." In total, 84\% (32 out of 38) of the respondents answered that it is helpful.

In Fig 9, 26\% of the respondents strongly agree, and 58\% agree that presentations are helpful. When comparing the data in Fig 8 and Fig 9, 26\% of the respondents in Fig 9 strongly agree that presentations are helpful, while $13 \%$ of the respondents in Fig 8 strongly agree that projects are helpful, though the almost same number of students, 33 students in Fig 8 and 32 students in Fig 9, answered either "Strongly Agree" or "Agree." So, more students strongly agreed that preparing the presentation is helpful to know the engineering major. Therefore, it can be concluded that preparing a presentation is more effective to know the engineering major that students chose to study before taking this course. This might be because students gain a broader knowledge of the engineering major that they are interested in while they prepare the presentation than when they conduct the project. For example, when students conduct the gearbox project as the mechanical engineering project, they mainly experience the characteristics of conducting the gearbox project. However, they cannot experience the characteristics of conducting other various mechanical engineering projects. Thus, their experience of conducting projects in mechanical engineering is very limited. However, students can learn broader information about mechanical engineering when they prepare a presentation about mechanical engineering. Thus, students can learn more about mechanical engineering when they prepare a presentation. Accordingly, preparing presentations are more effective than conducting projects to gain the knowledge of engineering majors that students are interested in. 

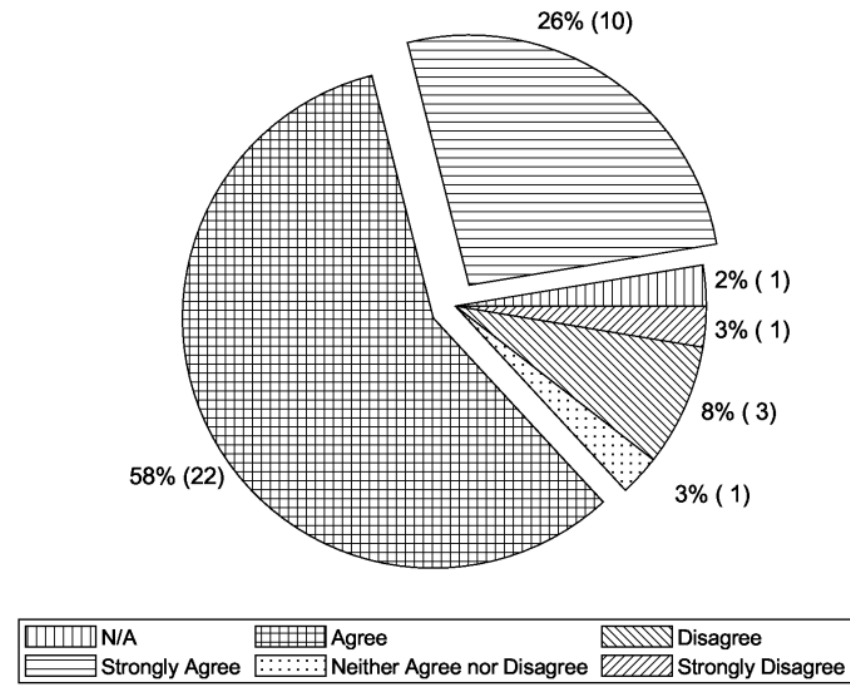

Fig. 9. Presentations help students know better the engineering major that they choose.

In Fig 10, it shows the responses from a question; whether conducting projects of the engineering major that students are interested in helps students strengthen their decision to study the engineering major. The results show that $13 \%$ (5 out of 38 ) of the respondents answered "Strongly Agree," and 76\% (29 out of 38) of the respondents answered, "Agree." In total, 89\% (34 out of 38) of the respondents answered it is helpful. In Fig 11, it shows the responses to a question, whether preparing the presentation about the engineering major that students are interested in help students to strengthen their decision to study the engineering major. The results show that $16 \%$ (6 out of 38 ) of the respondents answered "Strongly Agree," and 63\% (24 out of 38) of the respondents answered, "Agree." In total, 79\% (30 out of 38) of the respondents answered it is helpful. When comparing the data in Fig 10, and Fig 11, there is no significant difference for the answer of "Strongly Agree." However, more students answered "Agree" for the question corresponding to Fig 10 than the question corresponding to Fig 11. That means participants felt that conducting projects of the engineering major that students are interested in is more effective than preparing the presentation to strengthen their decision to study the engineering major. 


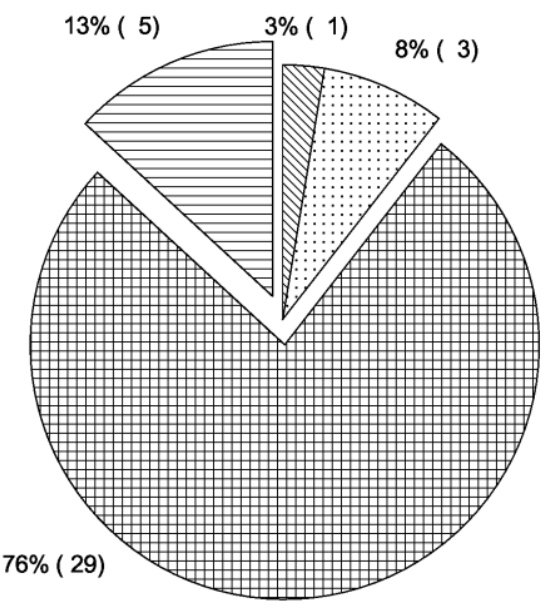

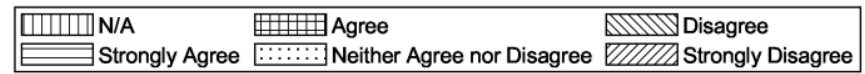

Fig. 10. Projects help students strengthen the decision to study the engineering major that they choose.

When comparing the responses in Fig 8 and Fig 9 in the previous paragraph, it indicates that preparing presentations is more effective than conducting projects to know better about the engineering major that students are interested in. On the contrary, when it comes to strengthening their decision to study the engineering major, conducting projects is more effective than preparing the presentation about the engineering major. Accordingly, students can learn more about the engineering major from preparing the presentation, while they can strengthen their decisions to study the engineering major from conducting the project. This may be because students usually choose to study a particular engineering major by learning the general information about the major, then they can enhance or confirm their choice when they work on the project related to the engineering major. 


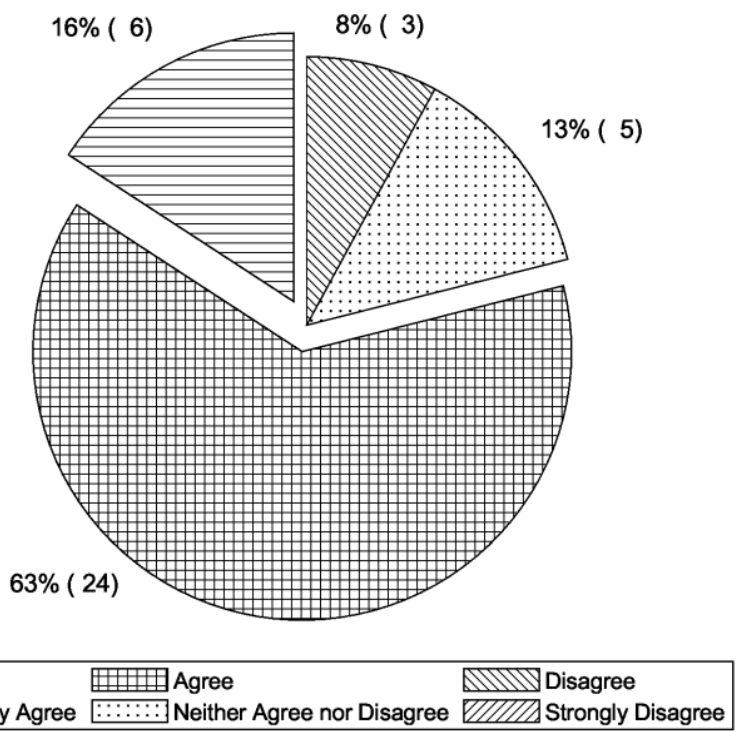

Fig. 11. Presentations help students strengthen the decision to study the engineering major that they choose.

At this point, it would be noteworthy to find how many students were influenced to decide to study engineering or not to study engineering after completing projects. Also, it would be interesting to know how many students decided to change their engineering major after completing projects and presentations. Fig 12 shows the responses for a question; whether conducting projects affect students to decide to study engineering if they did not intend to study engineering before taking this course. The data shows that $6 \%$ (3 out of 52) of the respondents answered "Strongly Agree," and 13\% (7 out of 52) of the respondents answered, "Agree." In total, 19\% (10 out of 52) of the respondents answered that conducting projects affected their decision to study engineering though they did not intend to study engineering before taking this course. This shows that conducting projects influenced some students who did not intend to study engineering before taking this course to study engineering. 
$4 \%$ ( 2)

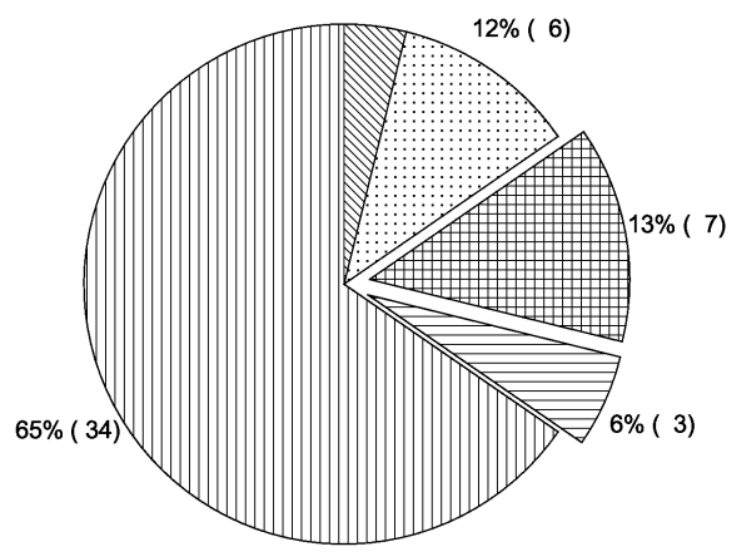

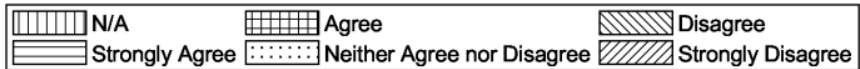

Fig. 12. Projects affect students who did not intend to study engineering before taking this course to decide to study engineering.

It is expected that students who intended to study engineering before taking this course answered "N/A" for the question corresponding to this figure. However, among students who intended to study engineering before taking this course, there might be some students who answered, "Neither Agree nor Disagree" for this question, instead of "N/A." Then, if it is assumed that those students who answered "Neither Agree nor Disagree" did not intend to study engineering before taking this course, it can be said that, at most, 40 students, which is the sum of number of responses from "N/A" and "Neither Agree nor Disagree," intended to study engineering before taking this course. That means, at least 12 out of 52 students did not intend to study engineering before taking this course. Then, according to the data, 10 out of 12 students were affected to decide to study engineering by conducting projects though they did not intend to study engineering before taking this course. This implies that conducting projects affect students effectively to decide to study engineering. That means conducting projects is a very effective way for students to know and understand what engineering is and how engineers work. It may be argued that the proportion of 10 out of 12 is unrealistically high. However, it would make sense if it is considered that students who choose to take this course might consider studying engineering as their major though they are not entirely sure. Accordingly, it makes sense to conclude that students want to find out by taking this course whether or not engineering is good for them to study. Thus, they will easily decide to study engineering after taking this course if they find out that engineering is good for them to study.

In Fig 13, it shows the responses to a question of whether conducting projects affect students' decision not to study engineering. The data shows that $2 \%$ (1 out of 52$)$ of the 
respondents answered, "Strongly Agree," and 21\% (11 out of 52) of the respondents answered, "Agree." In total, 23\% (12 out of 52) of the students answered that they were affected to decide not to study engineering after conducting projects. Therefore, it can be said that conducting projects affected more than a few students who intended to study engineering before taking this course to decide not to study engineering after taking this course. Thus, it tells that conducting projects is definitely effective for students to understand what engineering is and how engineers work, so that students can make better decisions whether they should study engineering as their major or not.

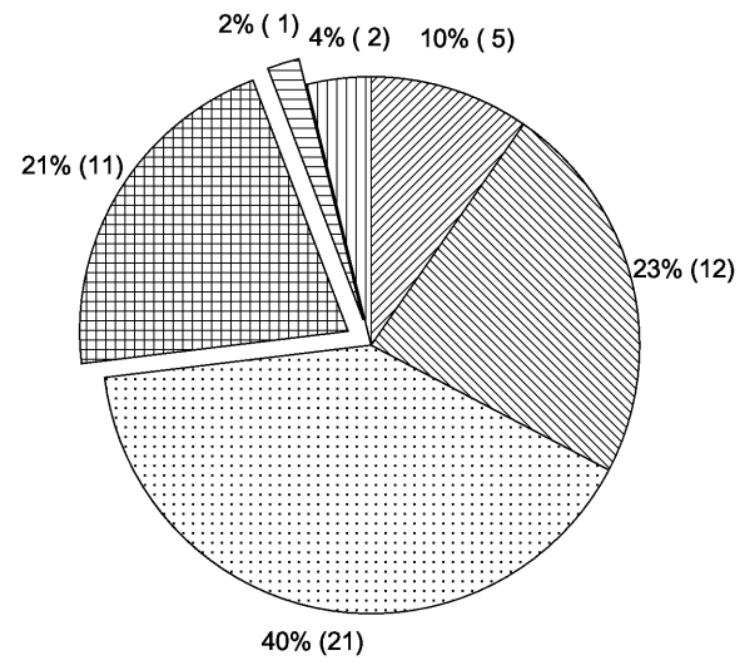

\begin{tabular}{|c|c|c|}
\hline |णس冂) N/A & 曲曲Agree & MUMD Disagree \\
\hline Strongly Agree & :::::: Neither Agree nor Disagree & Strongly Disagree \\
\hline
\end{tabular}

Fig. 13. Projects affect students who intended to study engineering before taking this course to decide not to study engineering.

Fig 14 shows the responses for a question; whether conducting projects affect students' decision to change their engineering major. As the question corresponding to Fig 14 was designed for the students who already decided their engineering major before taking this course, the data in this figure were collected from students who already determined their engineering major before taking this course. The data in the figure shows that 8\% (3 out of 38) of the respondents answered "Strongly Agree," and 24\% (9 out of 38 ) of the respondents answered, "Agree." In total, 32\% (12 out of 38) of the respondents answered that conducting projects affected their decision to change their engineering major. Thus, this tells that conducting projects is helpful for students to decide their engineering major. After tracking responses from these 12 students individually, it is worth mentioning that 6 out of 12 responses of "Strongly Agree" or "Agree" in Fig 14 means changing the major from an engineering major to a non-engineering major. That 
means 6 out of 12 students who answered that conducting projects affected their decision to change their engineering major decided to change their major to a non-engineering major after taking this course.

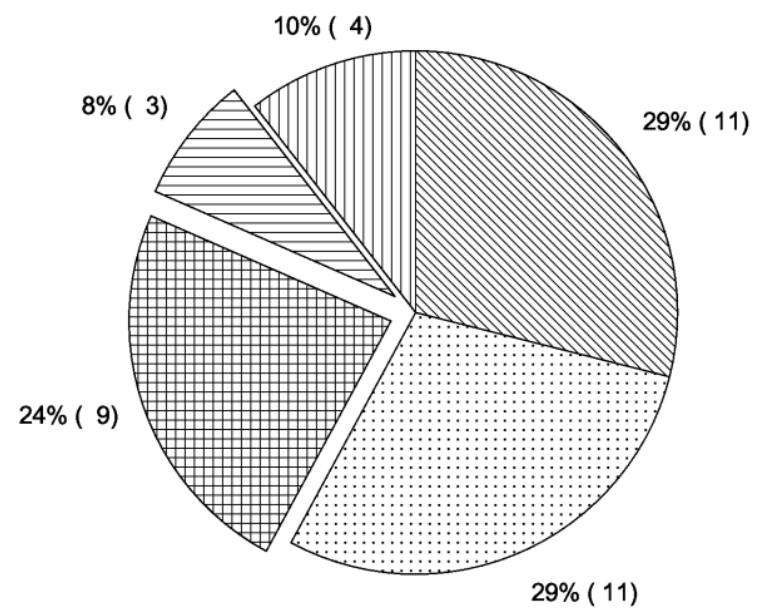

\begin{tabular}{|c|c|c|}
\hline 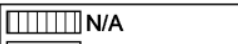 & 世曲Agree & MMUD Disagree \\
\hline 目Strongly Agree & a::::D Neither Agree nor Disagree & ZIIIIA Strongly Disagree \\
\hline
\end{tabular}

Fig. 14. Projects affect students to change the engineering major that they chose before taking this course.

Fig 15 shows the responses from a question of whether presentations affect students' decision to change their engineering major. Just as the question corresponding to Fig 14, the question corresponding to Fig 15 was also designed for students who already decided their engineering major before taking this course. Thus, the data in this figure were collected from students who already determined their engineering major before taking this course. Out of 52 students, 38 students already determined their engineering major before taking this course. The data in Fig 15 shows that $18 \%$ (7 out of 38) of the respondents answered "Agree," and no one answered, "Strongly Agree." Similar to the analysis in Fig 14, it is worth mentioning that 2 out of 7 responses of "Agree" actually means changing the major from an engineering major to a non-engineering major. That is, 2 out of 7 students who answered that presentations affect their decision to change their engineering major changed their major to a non-engineering major after taking this course. 


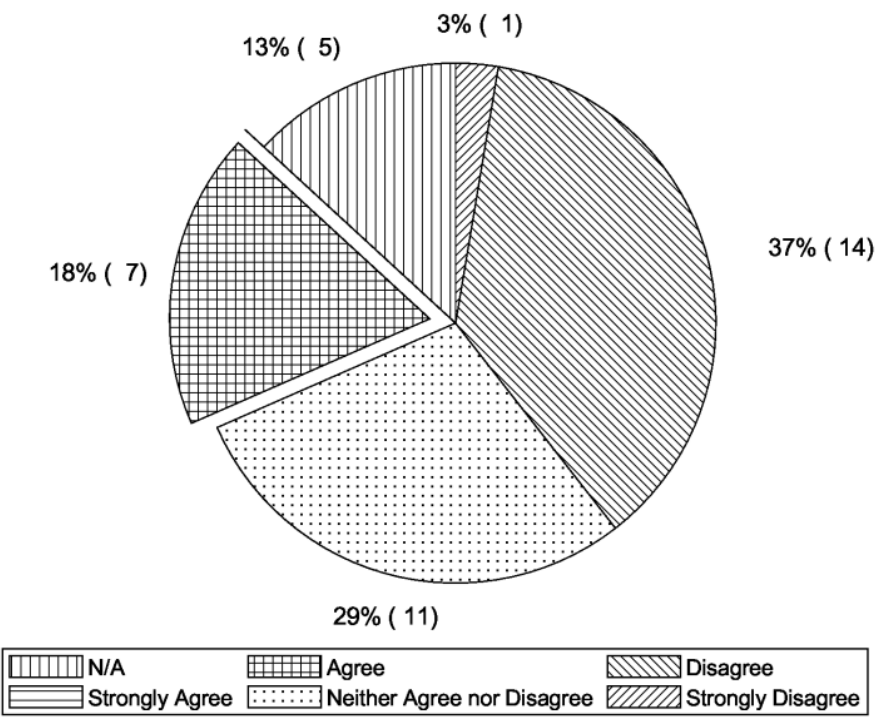

Fig. 15. Presentations affect students to change the engineering major that they chose before taking this course.

To compare the data in Fig 14, and Fig 15, more students were affected by projects than presentations to change their major. In Fig 15, no one answered that they were strongly affected by presentations to change their major. This indicates that projects are more effective when it comes to decisions of changing majors. The reason may be that working on the project in a specific engineering major is quite different from just having the general knowledge about the engineering major. That is, students might find interest in specific engineering major after gaining information about it, and they might consider studying it as their major. However, they would realize when they work on projects that it is not what they expected from the general information about the engineering major. If that is the case, then it means that working on a project has a very critical role for students to learn about the engineering major that students are interested in because it can provide information that students cannot gain from just knowing about the engineering major.

Fig 16 shows the overall satisfaction of the students with the course. The data shows that 21\% (11 out of 52) of the respondents answered "Very Satisfied," and 56\% (29 out of 52) of the respondents answered, "Satisfied." In total, 77\% (40 out of 52) of the students were satisfied with the course. One very promising thing about this course is that only one student answered "Dissatisfied," and no one answered "Very Dissatisfied." However, when it is considered that $92 \%$ of students agree in Fig 7 that they understand what engineering is and how engineers work from this course, which is one of the most important objectives of this course, then it would be expected that a similar percentage of students would be satisfied with this course. However, only $77 \%$ of students are satisfied with this course, as shown in Fig 16. It is unclear why $21 \%$ (11 out 
of 52) of students in Fig 16 answered, "Neither Satisfied nor Dissatisfied." Out of the responses of that $21 \%$ (11 out of 52) students in Fig 16, 2 students answered "Strongly Agree," and 7 students answered, "Agree," and only 2 students answered "Neither Agree nor Disagree" for the question corresponding to Fig 7. This indicates that those students were neither satisfied nor dissatisfied with the course though they achieved what they are supposed to learn from the course. Thus, it needs further study to understand the reasons why students gave these ratings and to improve the course by responding to the reasons they were not satisfied.

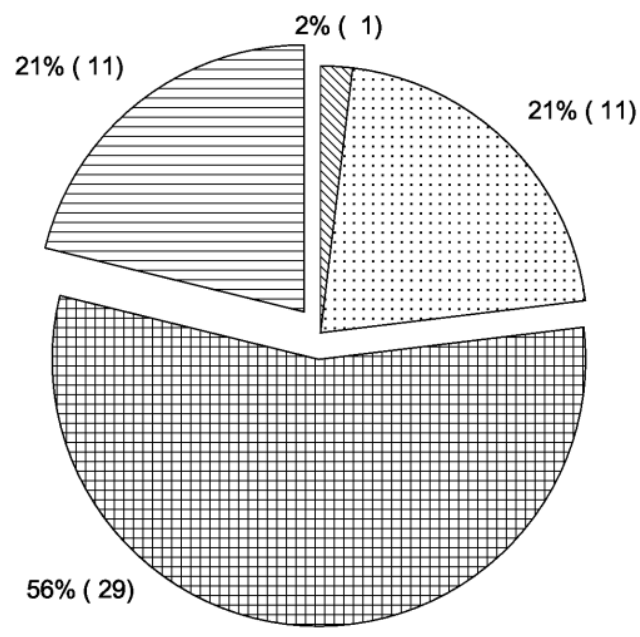

\begin{tabular}{|c|c|c|}
\hline$\overline{10}$ N/A & 曲曲 Satisfied & MIIIVD \\
\hline
\end{tabular}

Fig. 16. Overall satisfaction of the students with the course.

Even though the survey responses show promising results, some limitations need to be discussed about the new course. First, the projects and presentations cannot give nor provide all of the information that students need to know to choose their engineering major. For example, students conduct a project of a movable bridge with a hydraulic system using popsicle sticks and syringes as a civil engineering project in this course. However, conducting this project does not give all the characteristics of various projects in civil engineering. This limitation also applies to the presentations. Preparing the presentation about a specific engineering major cannot give all the information about the engineering major. It is not practically possible to learn all the information about a particular engineering major by conducting a couple of projects and preparing a presentation of that major. However, even though it is practically impossible to get all information from projects and presentations, it is still worthwhile to improve existing projects or develop new projects so that students get the information as much as possible to choose their engineering major. One suggestion is to include a service learning project into the course. A study that was performed about effects of a service learning 
course for the first year engineering students showed that the students learned the need of abilities required to conduct a real world engineering project [21]. Therefore, adding a serve learning project would help students learn how egnineers in the real world work to solve engineering problems.

Additionally, an improved direction for preparing a presentation about an engineering major is needed, so that students can get a better understanding of the engineering major from preparing the presentation. Second, the survey responses were collected only one semester after the new course was offered. Therefore, it is not guaranteed that the responses from the students who participated in the survey represent the general population of the pre-engineering students. Thus, more survey responses in the future are needed to represent the students more precisely to improve the course quality. Finally, the effect of the presentations on the general information of engineering given by an instructor was not considered in this survey. It may be possible that those presentations would affect the survey results of the overall satisfaction with this course. More elaborated questions to survey the overall satisfaction with this course need to be developed to reduce the effect of the presentations for future studies.

\section{Conclusion}

A considerable number of students enroll in engineering programs each year, while many of them do not have a good idea of what engineering is or what engineers do. Institutions having their various engineering departments can offer the Introduction to Engineering courses to provide general information about engineering and various engineering disciplines to help the $1^{\text {st }}$ year engineering students choose their engineering major. However, colleges that have only pre-engineering programs without any specific engineering department do not have adequate available resources to offer the course as those colleges that have their various own engineering departments. To help those preengineering students at the institutions without any specific engineering department, a new course was designed and suggested in this paper.

A survey was carried out to determine the effectiveness of the new course. The survey result showed that the new course is very effective for pre-engineering students to understand what engineering is and what engineers do. It also showed that conducting projects and preparing presentations related to various engineering majors is a very effective method to support students in developing an understanding of each engineering discipline and enhance their decision to study the engineering major that they choose. It was reported that some of the students were affected to decide to study engineering, and some of them were affected to decide not to study engineering after conducting projects. It was also reported that some of the students were affected to change their engineering major after conducting projects and preparing presentations.

From analyzing the survey responses, it showed that the students learn better about a specific engineering major from preparing a presentation about the engineering major, while they confirm more their decision to study the engineering major from conducting a project related to the engineering major. It also showed that conducting projects affected students who decided to change their major after taking this course more than 
preparing presentations. From this analysis, it can be concluded that conducting a project has a very critical role to play for the students in the process of decision making regarding choosing their engineering major because it gives information that students cannot get just from sitting through a lecture about the engineering major. The survey results also show that the majority of the students were overall satisfied with the course. Therefore, this new course is very effective for pre-engineering students to know what engineering is and what engineers do. It is also very effective for pre-engineering students to choose or confirm their engineering major.

However, in future iterations of this course, the existing projects need to be improved, or new projects need to be designed to represent the characteristics of projects of each engineering major better. Also, it is recommended to have a better direction for preparing a presentation about each engineering major, so that students can gain more effective information while choosing their engineering major. Lastly, it is desired to conduct more surveys better to represent the general population of pre-engineering students.

\section{References}

[1] X. Chen and M. Soldner, "STEM Attrition: College Students' Paths Into and Out of STEM Fields," National Center for Education Statistics, Statistical Analysis Report NCES 2014001REV, Nov. 2013.

[2] B. L. Yoder, "Engineering by the Numbers," American Society for Engineering Education, 2017.

[3] M. R. Anderson-Rowland, A. Rodriguez, and A. Grierson, "Why some community college students choose engineering and some don't," in Proceedings, ASEE Annual Conference and Exposition, Atlanta, GA, 2013.

[4] C. Atman et al., "Moving From Pipeline Thinking To Understanding Pathways: Findings From The Academic Pathways Study Of Engineering Undergraduates," in Proceedings, 2008 Annual Conference and Exposition, Pittsburgh, Pennsylvania, 2008.

[5] O. Eris et al., "A Preliminary Analysis Of Correlates Of Engineering Persistence: Results From A Longitudinal Study," in Proceedings, 2007 Annual Conference and Exposition, Honolulu, Hawaii, 2007.

[6] R. Marra, B. Bogue, D. Shen, and K. Rodgers, "Those That Leave - Assessing Why Students Leave Engineering," in Proceedings, 2007 Annual Conference and Exposition, Honolulu, Hawaii, 2007.

[7] M. Watson, S. Ghanat, D. Michalaka, K. Bower, and R. Welch, "Why Do Students Choose Engineering? Implications for First-Year Engineering Education," in Proceedings of the 7th First Year Engineering Experience (FYEE) Conference, Roanoke, VA, 2015.

[8] J. S. Noonan, W. C. Oakes, and P. K. Imbrie, "FIRST-YEAR ENGINEERING STUDENTS' CHOICE OF A MAJOR: WHEN IT IS MADE AND WHAT INFLUENCES IT," presented at the 2006 Illinois-Indiana and North Central Joint Section Conference, Fort Wayne, Indiana, 2006.

[9] M. Carnasciali, A. Thompson, and T. Thomas, "Factors influencing students' choice of engineering major," in Proceedings, 2013 ASEE Annual Conference and Exposition, Atlanta, Georgia, 2013. 
[10] I. Ngambeki, O. Dalrymple, and D. Evangelou, "Decision Making In First Year Engineering: Exploring How Students Decide About Future Studies And Career Pathways," in Proceedings, 2008 Annual Conference and Exposition, Pittsburgh, Pennsylvania, 2008.

[11] J. C. McNeil, P. A. Miller, and J. J. Saleem, "Influential Factors on Selecting an Engineering Major in a First-Year Course," J. Prof. Issues Eng. Educ. Pract., vol. 145, no. 2, p. 04019001, Apr. 2019, https://doi.org/10.1061/(ASCE)EI.1943-5541.0000405

[12] X. Chen, C. E. Brawner, M. W. Ohland, and M. K. Orr, "A Taxonomy of Engineering Matriculation Practices," in Proceedings, 2013 ASEE Annual Conference and Exposition, Atlanta, Georgia, 2013.

[13] M. Hoit and M. Ohland, "The Impact of a Discipline-Based Introduction to Engineering Course on Improving Retention," J. Eng. Educ., vol. 87, no. 1, pp. 79-85, Jan. 1998, https://doi.org/10.1002/j.2168-9830.1998.tb00325.x

[14] W. LeBold, H. Diefes, and W. Oakes, "Helping First Year Students Make Critical Career Decisions," in Proceedings, 1999 Annual Conference, Charlotte, North Carolina, 1999.

[15] C. Rowe and A. Mahadevan-Jansen, "Getting To Know Your Engineering Major," in Proceedings, 2003 Annual Conference, Nashville, Tennessee, 2003.

[16] S. Zahorian, M. Elmore, and K. J. Temkin, "Factors that Influence Engineering Freshman to Choose Their Engineering Major," in 2013 ASEE Annual Conference and Exposition, Atlanta, Georgia, 2013.

[17] T. VanDeGrift and S. Liao, "Helping First-Year Engineering Students Select a Major," in Proceedings, 2017 ASEE Annual Conference and Exposition, Columbus, Ohio, 2017.

[18] P. Taheri, "Project-Based Approach in a First-Year Engineering Course to Promote Pro-ject Management and Sustainability," Int. J. Eng. Pedagogy IJEP, vol. 8, no. 3, p. 104, May 2018, doi: 10.3991/ijep.v8i3.8573. https://doi.org/10.3991/ijep.v8i3.8573

[19] K. R. Galloway and S. L. Bretz, "Development of an Assessment Tool To Measure Students' Meaningful Learning in the Undergraduate Chemistry Laboratory," J. Chem. Educ., vol. 92, no. 7, pp. 1149-1158, Jul. 2015, https://doi.org/10.1021/ed500881y

[20] W. C. Oakes, L. L. Leone, C. J. Gunn, and J. L. Gruender, Engineering your future: a comprehensive introduction to engineering, Eighth edition. New York: Oxford University Press, 2015.

[21] D. Budny, L. Lund, and R. Khanna, "Designing Service Learning Projects for Freshman Engineering Students," Int. J. Eng. Pedagogy IJEP, vol. 3, no. S1, p. 31, Feb. 2013, https://doi.org/10.3991/ijep.v3iS1.2371

\section{$7 \quad$ Author}

Il Yoon is an Assistant Professor and the Pre-engineering program Coordinator for the department of Physics and Astronomy at the University of North Georgia. Email: iyoon@ung.edu

Article submitted 2020-01-08. Resubmitted 2020-03-02. Final acceptance 2020-03-02. Final version published as submitted by the authors. 